\title{
Maternal \& Foetal Outcome in Cases of Pre-Labour Rupture of Membranes
}

\author{
Rauf Abdul ${ }^{1}$, Mehta Seema ${ }^{2}$ Beniwal Nabab Singh ${ }^{3}$ \\ ${ }^{z 1}$ (Obstetrics\& Gynaecology Department, S.M.S. Medical College, Rajasthan University of Health Sciences) \\ ${ }^{2}$ (Obstetrics\& Gynaecology Department, S.M.S. Medical College, Rajasthan University of Health Sciences) \\ ${ }^{3}$ (Obstetrics\& Gynaecology Department, S.M.S. Medical College, Rajasthan University of Health Sciences)
}

\begin{abstract}
:
OBJECTIVE: In this study, we aimed to evaluate maternal \& foetal outcome in cases of pre-labour rupture of membranes.
\end{abstract}

STUDY DESIGN: This was a prospective study of 200 cases of pre-labour rupture of membranes coming to the Dept. of Obst \& Gynae, SMS Medical College, Jaipur

METHOD: The cases included were singleton pregnancies with gestational age of 28 weeks or more with spontaneous rupture of membranes. Cases with severe PIH / Eclampsia / severe anemia, with any medical disorder and absolute indication of LSCS were excluded from study.

Mother observed for maternal morbidity i.e. PPH, retained placenta, puerperal pyrexia, subinvolution of uterus, wound infection, phlebitis\& endometritis.

Condition and weight of newborn at the time of delivery was noted. Condition of baby during its hospital stay was observed carefully. All infants were observed for neonatal morbidity and perinatal mortality.

Maternal \& neonatal morbidity and mortality recorded.

RESULTS : In our study total maternal morbidity was $21.5 \%$ total neonatal morbidity was $24.5 \%$. The most common neonatal morbidity noted in our study was neonatal septicemia followed by birth asphyxia \&pneumonia. Total perinatal loss was $13 \%$.

There was definite increase in maternal morbidity, neonatal morbidity \&perinatal mortality with increase in duration between rupture of membranes \& delivery.

CONCLUSION: Maternalmorbidity, neonatal morbidity\&perinatal mortality increases as interval between ROM \& delivery increases.

Keywords: Maternal, Morbidity, PROM, Puerperal pyrexia, Vaginal swab.

\section{Introduction}

Prelabour rupture of membrane is one of the most common clinical problem where a normal pregnancy can turn into a high risk situation for the mother and the foetus.

Prelabour rupture of membranes (PROM) is defined by the American College of Obstetrics and Gynaecology (Gunn et al., 1970)[1]-as spontaneous rupture of membranes prior to the onset of regular uterine contractions.

Duff P. (1996) has defined that PROM is a rupture of membranes before labour begins \& he also stated that at least $60 \%$ cases of PROM occur at term [2].

The function of the amniotic fluid is mainly protective. It assists in maintaining an even temperature, acts as a buffer against external injuries, equalizes pressure, allows free movements of the fetus, prevents adhesions between the amnion and the fetal skin, provides passive immunity of the foetus in the form of gamma globulin antibodies, checks the ascending infections, and during labour, acts as a dilating wedge in the cervix, so long as the amnion remains intact.

Pre mature rupture of membrane is one of the most common complication of pregnancy that has a major impact on neonatal outcome [3].

Amongthe many aetiologies of perinatal deaths, prematurity is the most frequent offender and when specific etiology of prematurity group is assessed, PROM account for 35\% of preterm deliveries (Pandey swati et al. 2000) [4]. Clearly any serious attempt to decrease the morbidity and mortality due to prematurity must address the prevention and proper therapy of PROM.

Exact etiology of PROM is not known, it is the result of various biochemical and mechanical pathway leading to weakness of choriomnion (relative or absolute) that allow rupture.

Microrgainism may gain access to the intra-amniotic cavity using following pathways

1. Ascending from vagina and cervix -

2. Hematogenous through Placenta (Trans Placental) 
3. Accidental introduction at time of intrauterine procedure example - Amniocentesis, Cordiocentesis.

4. Repeated Ante partum pelvic examination

Study design

\section{Method}

This study was carried out in Obstetrics and Gynaecology Department, SMS Medical College, Jaipur and included 200 cases of prelabour rupture of membrane.

Duration of Study - 1 year

Sample size calculated as 200 women with $\alpha$ error of $0.05, \beta$ error of 0.2 and study power of $80 \%$.

The cases included were singleton pregnancies with gestational age of 28 weeks or more and with spontaneous rupture of membranes. Cases with severe PIH / Eclampsia / severe anemia, with any medical disorder and absolute indication of LSCS were excluded from study.

All selected cases were subjected to general physicalexamination with special emphasis on temperature, pulse, blood pressure, edema feet, status of heart and lungs.

Obstetric examination was done to know the maturity of fetus in weeks, presentation and position of fetus, fetal heart sounds and any tenderness on palpation. All cases were subjected to detailed ultrasonographic assessment. Prophylactic antibiotic administered to all cases. Vaginal examination was done, under all aseptic precautions to note dilatation of os, effacement of cervix, presence or absence of membranes, absence of bag of membranes when membranes intact (high leak), presentation, station and position of presenting part, and presence of leaking noted. Pelvic assessment was done simultaneously.

The cases were kept under observation for progress of labour. If labour did not start spontaneously then it was induced either by prostaglandin gel or intravenous oxytocin after ruling out the contraindications.

Close monitoring of progress of labour was done. Rupture of membrane to delivery interval noted \& mode of delivery noted.

The mother was observed carefully during her puerpurial hospital stay, with special emphasis on temperature, pulse, lochia and involution.

Mothers observed for any postpartumhaemorrhage, Retained Placenta, PuerpuralPyrexia,Sublinvolution of uterus, Wound Infection, Phlebitis\&Endometritis.

Condition \& weight of new born at the time of delivery was noted.

Condition of the baby during its hospital stay observed carefully. All infants observed for anyneonatalmorbidity and perinatal mortality. Maternal \& neonatal morbidity and mortality recorded.

\section{Result}

TABLE - $1 \quad$ Distribution of cases

\begin{tabular}{|l|l|}
\hline & Study Group \\
\hline Mean Age & $23.45 \pm 3.75$ yrs \\
\hline Mean Parity & 1.04 \\
\hline Mean gestational age & 36.07 wks. \\
\hline
\end{tabular}

Table 1 depicts distribution of cases of study group. Mean age was $23.45 \pm 3.75$ yrs, mean parity was $1.04 \&$ mean gestational age was36.07 wks.

TABLE - 2 Distribution of cases according to ROM to delivery interval

\begin{tabular}{|l|l|l|}
\hline ROM to delivery interval & No. of cases & $\mathbf{\%}$ \\
\hline$<12$ hrs. & 58 & 29 \\
$13-24$ hrs. & 73 & 36.5 \\
$25-48$ hrs. & 32 & 16 \\
$>48$ hrs. & 37 & 18.5 \\
\hline
\end{tabular}

Maximum patients delivered before 24 hours i.e. 131(65.5\%)

Table 2 depicts rupture of membrane to delivery interval. Maximum $131(65.5 \%)$ cases delivered before $24 \mathrm{hrs}$. $32(16 \%)$ cases delivered between $24-48$ hrs. of PROM \& 37 (18.5\%) cases delivered after $48 \mathrm{hrs}$.

TABLE - 3 Distribution of cases according to Onset / Augmentation of Labor

\begin{tabular}{|l|l|l|}
\hline Labor & Total & Percentage \\
\hline Spontaneous onset & 57 & 28.5 \\
Successful & 46 & 23.0 \\
Failed to progress & 5 & 2.5 \\
Foetal distress & 6 & 3.0 \\
\hline Prostaglandin gel alone & 51 & 25.5 \\
Successful & 40 & 20.0 \\
Failed to progress & 5 & 2.5 \\
Foetal distress & 6 & 3.0 \\
\hline
\end{tabular}




\begin{tabular}{|l|l|l|}
\hline Prostaglandin gel & 29 & 14.5 \\
F/b Oxytocin & 12 & 6.0 \\
Successful & 5 & 2.5 \\
Failed to progress & 12 & 6.0 \\
Foetal distress & 63 & 31.5 \\
\hline Oxytocin & 30 & 15.0 \\
Successful & 23 & 11.5 \\
Failed to progress & 10 & 5.0 \\
\hline Foetal distress &
\end{tabular}

Table 3 depicts distribution of cases according to onset / augmentation of labour.

Mode of labour in 57 (28.5\%)cases was spontaneous out of which 46 cases delivered successfully. 51 cases (25.5\%) were given prostaglandin gel alone out of which $40(20 \%)$ delivered successfully, 29 cases $(14.5 \%)$ were given prostaglandingel followed by oxytocin out of which 12 patients $(6 \%)$ delivered successfully, 63 cases $(31.5 \%)$ were given oxytocin alone out of which only 30 cases $(15 \%)$ delivered successfully. So overall in 143 cases $(71.5 \%)$ labour was augmented, out of which 82 cases $(57.34 \%)$ delivered successfully. Thisshows that timely augmentation by PGE2 Gel or Oxytocin increases the chances of successful vaginal delivery.

TABLE - 4 Distribution of cases according to mode of delivery

\begin{tabular}{|l|l|l|l|l|l|}
\hline $\begin{array}{l}\text { ROM to delivery } \\
\text { interval }\end{array}$ & No. of cases & Vaginal delivery & Percentage & $\begin{array}{l}\text { Caesarean } \\
\text { Section }\end{array}$ & Percentage \\
\hline$<12$ hrs. & 58 & 46 & 79.31 & 12 & 20.68 \\
$13-24$ hrs. & 73 & 54 & 73.97 & 19 & 26.02 \\
$25-48$ hrs. & 32 & 14 & 43.75 & 18 & 56.25 \\
$>48$ hrs. & 37 & 14 & 37.83 & 23 & 62.16 \\
\hline Total & 200 & 128 & 64 & 72 & 36 \\
\hline
\end{tabular}

In our study in Pre-labour rupture of membranes caesarean section rate was $36 \%$.

Table 4 depict distribution of cases according to mode of delivery. Total 128 cases (64\%) delivered vaginally \& in 72 cases (36\%) LSCS done. With increase in duration of rupture of membrane to delivery caesarean section rate also increases.

TABLE - 5 Association of Maternal Morbidity to interval between ROM \& delivery

\begin{tabular}{|l|l|l|l|l|l|l|l|l|l|}
\hline \multirow{2}{*}{$\begin{array}{l}\text { ROM to delivery } \\
\text { interval }\end{array}$} & \multirow{2}{*}{ No. of cases } & \multicolumn{2}{|c|}{ Puerperal Pyrexia } & \multicolumn{2}{|l|}{ Wound infection } & PPH & \multicolumn{2}{l|}{ Total maternal morbidity } \\
\cline { 3 - 9 } & & No. & $\%$ & No. & $\%$ & No. & $\%$ & No. & $\%$ \\
\hline$<12$ hrs. & 58 & 2 & 3.7 & 2 & 3.77 & 4 & 7.5 & 8 & 15.09 \\
$13-24$ hrs. & 73 & 3 & 4.2 & 3 & 4.28 & 8 & 11.4 & 14 & 20 \\
$25-48$ hrs. & 32 & 3 & 10 & 3 & 10 & 2 & 6.66 & 8 & 25 \\
$>48$ hrs. & 37 & 6 & 16.21 & 5 & 13.51 & 2 & 5.4 & 13 & 35.13 \\
\hline Total & 200 & 14 & 7 & 13 & 6.5 & 16 & 8 & 43 & 21.5 \\
\hline
\end{tabular}

Table 5depicts the relationship of maternal morbidity with interval between rupture of membranes \& delivery. When rupture of membrane to delivery interval was $<24$ hrs maternal morbidity was seen in $16.79 \%$ cases, while it was in $25 \%$ cases when ROM to delivery interval was $24-48$ hrs\& it was in $35.13 \%$ cases when ROMdelivery interval was $>48 \mathrm{hrs}$. In our study there was increased maternal morbidity with increase in interval between rupture of membranes and delivery.

The rate of maternal morbidity in this study was $21.5 \%$ high compared to previous study by Vermillionet al[5] but almost similar rate reported by Yoonet al.[6]\& OkekeTc et

TABLE - 6 Distribution of Neonatal Morbidity according to duration of ROM and delivery

\begin{tabular}{|c|c|c|c|c|c|c|c|c|c|c|c|c|c|}
\hline $\begin{array}{l}\text { Duration } \\
\text { of ROM } \\
\& \\
\text { delivery }\end{array}$ & $\begin{array}{l}\text { Total } \\
\text { birth }\end{array}$ & $\stackrel{\mathscr{A}}{\simeq}$ & $\begin{array}{l}\text { Pneu- } \\
\text { monia }\end{array}$ & $\sum_{\Sigma}^{n}$ & $\begin{array}{l}\text { N. } \\
\text { Septi- } \\
\text { caemia }\end{array}$ & $\begin{array}{l}\mathrm{N} . \\
\text { Jaun- } \\
\text { dice }\end{array}$ & $\begin{array}{l}\text { Hypo- } \\
\text { ther-mia }\end{array}$ & $\begin{array}{l}\text { Cong. } \\
\text { Mal. }\end{array}$ & $\begin{array}{l}\text { Birth } \\
\text { as- } \\
\text { phy- } \\
\text { xia } \\
\end{array}$ & 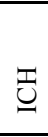 & $\begin{array}{l}\text { Pulmonary } \\
\text { haemorrhage }\end{array}$ & $\begin{array}{l}\text { Total } \\
\text { neonatal } \\
\text { morbidity }\end{array}$ & $\%$ \\
\hline $\begin{array}{l}<12 \text { hrs. } \\
12-24 \text { hrs. } \\
25-48 \text { hrs. } \\
>48 \text { hrs. }\end{array}$ & $\begin{array}{l}58 \\
73 \\
32 \\
37 \\
\end{array}$ & $\begin{array}{l}2 \\
3 \\
- \\
-\end{array}$ & $\begin{array}{l}2 \\
2 \\
2 \\
3 \\
\end{array}$ & $\begin{array}{l}1 \\
1 \\
1 \\
1 \\
\end{array}$ & $\begin{array}{l}2 \\
1 \\
3 \\
8 \\
\end{array}$ & $\begin{array}{l}1 \\
2 \\
1 \\
1 \\
\end{array}$ & $\begin{array}{l}- \\
1 \\
- \\
-\end{array}$ & $\begin{array}{l}- \\
1 \\
- \\
- \\
\end{array}$ & $\begin{array}{l}- \\
1 \\
3 \\
5 \\
\end{array}$ & $\begin{array}{l}- \\
- \\
- \\
-\end{array}$ & $\begin{array}{l}- \\
1 \\
- \\
-\end{array}$ & $\begin{array}{l}8 \\
13 \\
10 \\
18 \\
\end{array}$ & $\begin{array}{l}13.79 \\
17.80 \\
31.25 \\
48.64 \\
\end{array}$ \\
\hline Total & 200 & 5 & 9 & 4 & 14 & 5 & 1 & 1 & 9 & 0 & 1 & 49 & 24.5 \\
\hline
\end{tabular}

Table 6 depicts distribution of neonatal morbidity according to duration of rupture of membranes \& delivery. In our studytotal Neonatal Morbidity was $24.5 \%$.

When rupture of membranes to delivery interval was $<24 \mathrm{hrs}$ neonatal morbidity was in 21 cases $(16.03 \%)$. While it was in 10 (31.25\%) cases when ROM to delivery interval was $24-48 \mathrm{hrs}$. \& it was in $18(48.64 \%)$ 
cases when ROM to delivery interval was $>48$ hrs. There was increased neonatal morbidity with increase in interval between ROM todelivery. The most common type of neonatal morbidity noted in our study was neonatal septicemia followed by birth asphyxia \& pneumonia.

TABLE - 7 Distribution according to Foetal Outcome

\begin{tabular}{|l|l|l|l|l|l|l|}
\hline Duration & No. of cases & Live birth & Still birth & $\%$ & Neonatal death \\
\hline$<12$ hrs. & 58 & 58 & 0 & 0 & 0 & 2 \\
$13-24$ hrs. & 73 & 73 & 0 & 0 & 6.25 & 6 \\
$25-48$ hrs. & 32 & 30 & 23 & 4 & 10.81 & 12 \\
$>48$ hrs. & 37 & 194 & 6 & 3 & 2.7 & 18.75 \\
\hline Total & 200 & 33 & 20 & 32.4 \\
\hline
\end{tabular}

Table 7 depictsfoetal outcome with relation to ROM delivery interval. When ROM-delivery interval was $<24 \mathrm{hrs}$ there were $2(1.5 \%)$ neonatal deaths\& no still birth was noted. When ROM-delivery interval was $24-48$ hrs there were $2(6.25 \%)$ still birth \& $6(18.75 \%)$ neonatal deathwhereas when ROM-delivery interval was $>48$ hrs there were $4(10.81 \%)$ still birth \& $12(32.4 \%)$ neonatal death. Total still births were $6(3 \%)$ \&neonatal death were 20 $(10 \%)$. Total Perinatal loss in our study was $26(13 \%)$, whereas $11.8 \%$ perinatal mortality was seen in a study by Renay Weiner, CarineRosmaus, Ed Dorman [8] et al.

\section{Conclusion}

Hence we conclude that prelabour rupture of membranes contribute significantly to maternal morbidity, neonatal morbidity \& perinatal mortality. We also found a strong correlation between the maternal \&neonatal morbidity \&perinatal mortality to the duration of rupture of membranes and delivery. With increase duration of rupture of membrane and delivery there was a definite increase in maternal \&neonatal morbidity \&perinatal mortality. Hence proper management and timely intervention will definitely bring down the maternal \& neonatal morbidity and perinatal mortality in prelabour rupture of membranes cases.

\section{References}

[1]. Gunn G.G., Mischell Morton: "PROM A review", AM. J. Obstet. Gynaecol 1970; 106:409.

[2]. Duff P. Premature rupture of membranes at term. N Eng. J Med. 1996; 334:1053.

[3]. Honnah ME, Ohlsson A, Farine D, Hewson SA, Hodnett ED, MyGr TL et. al. Induction of labour with expectant management of PROM at term. N Eng. J. Med. 1996; 334: 1005-10.

[4]. Pandey Swati, DavaAnupama, Bandi S. "Maternal and Foetal Outcome in cases of PROM". J. of Obstet. and Gynaecol India 2000; 50: 63 .

[5]. Vermillion ST, SoperDE,Chasedunn-Roark J. Neonatal sepsis after betamethasone administration to patients with preterm premature rupture of membranes. Am J Obstet Gynecol 1999; 181: 320-327.

[6]. Yoon BH, Kim YA, Romero R, Kim JC, Park KH, Kim MH,et al.Association of oligohydroamnios in women with preterm premature rupture of membranes with an inflammatory response in fetal, amniotic and maternal compartments. Am J Obstet Gynecol, 1999; 181: 784-788.

[7]. TC, Okeke, et al. "The Incidence and Management Outcome of Preterm Premature Rupture of Membranes (PPROM) ina Tertiary Hospital in Nigeria.” American Journal of Clinical Medicine Research 2.1 (2014): 14-17.

[8]. Renay Weiner, CarineRosmaus, Ed Dorman et al. Labour complications remain the most important risk factors for perinatal mortality in rural Kenya. Bull World Health Organ vol.81 n.8 Genebra Jan. 2003. 